\title{
PENGARUH PAKET “AVIL-PMS” TERHADAP PENGETAHUAN REMAJA PUTRI DI SMA “X” KOTA BANDUNG
}

\author{
Clara Yollanda $\mathbf{R}^{1)}$, Raden Nety Rustikayanti ${ }^{2)}$, Metha Dwi Tamara ${ }^{3)}$ \\ r4denty@gmail.com \\ ${ }^{1,2)}$ Program Studi Sarjana Keperawatan, STIKes Dharma Husada Bandung \\ ${ }^{3}$ Program Studi Sarjana Kesehatan Masyarakat, STIKes Dharma Husada Bandung
}

\begin{abstract}
About 7 until 10 days before the onset of menstruation, a young women will have a symptoms of physical or emotional changes known as Pre-menstrual Syndrome (PMS). Knowledge of Premenstrual Syndrome should already be known by young women. Giving knowledge can be done with health education by using Audiovisual leaflet pre-menstrual syndrom (AViL-PMS) as a media. This media is more interesting and effective because it involves two senses that is vision and hearing, so it can maximize the acceptance of information. This study aims to determine the influence of AViL-PMS health education about Pre-menstrual Syndrome (PMS) toward the knowledge of young women. This research is quantitative with quasi experimental study design. Sampling using purposive sampling with 42 respondents. Data collection using questionnaires, and data analysis technique using dependent T-test. The results indicate there is an influence of AViLPMS toward the knowledge ( $p$-value 0,000 $<\alpha=0,005$ ). Suggestions in this study for teachers and health workers to cooperate in providing health education on the importance of reproductive health, especially for young women.
\end{abstract}

Keywords: $\quad$ AViL-PMS,

\section{PENDAHULUAN}

Kesehatan reproduksi remaja merupakan suatu kondisi sehat yang menyangkut sistem, fungsi dan proses reproduksi yang dimiliki oleh remaja (Irianto, 2015). Kemenkes RI (2015) menyatakan remaja membutuhkan suatu pelayanan kesehatan reproduksi remaja yang bertujuan untuk mencegah dan melindungi remaja dari perilaku seksual berisiko yang dapat menimbulkan masalah terhadap kesehatan reproduksi.

Berbagai data menunjukkan bahwa penerapan pemenuhan reproduksi bagi remaja belum sepenuhnya mereka dapatkan antara lain dalam hal pemberian informasi. Hal ini dapat dilihat dari masih rendahnya pengetahuan remaja tentang kesehatan
Knowledge, Pre-Menstrual Syndrome reproduksi yaitu tentang masa subur (BKKBN, 2012).

Pengetahuan remaja di Indonesia tentang kesehatan reproduksi masih sangat rendah. Hasil Survei Dasar Kesehatan Indonesia tahun 2012, menyatakan bahwa kesehatan reproduksi remaja menunjukkan bahwa pengetahuan tentang akil balik pada wanita tertinggi saat mulai haid sebesar $74,9 \%$, payudara membesar $36,9 \%$ dan timbul jerawat $13,2 \%$, dan terendah menonjolkan jati diri $0,8 \%$, gairah seks meningkat 2,3\%, tertarik lawan jenis $6,4 \%$ (Kemenkes RI, 2015).

Remaja putri paling rentan dalam menghadapi masalah kesehatan sistem reproduksinya. Hal ini dikarenakan secara 
anatomis, remaja putri lebih mudah terkena infeksi dari luar karena bentuk dan letak organ reproduksinya yang dekat dengan anus (BKKBN, 2012). Dari 43.500.000 remaja di indonesia, jumlah remaja perempuan di Indonesia, yaitu 21.489.600 atau 18,11\% dari jumlah keseluruan remaja di Indonesia.

Pada masa ini remaja putri mengalami menstruasi sebagai tanda matangnya sistem reproduksi wanita. Sebanyak $75 \%$ remaja mengalami gejala menstruasi yang dapat mengganggu aktivitas sehari-hari dan emosional.

Pre-menstrual syndrome (PMS) merupakan suatu keadaan dimana sejumlah gejala seperti perubahan fisik, perubahan suasana hati, dan perubahan mental, terjadi secara rutin dan berhubungan dengan siklus menstruasi, gejala biasanya timbul 7-10 hari sebelum menstruasi dan menghilang ketika menstruasi dimulai (Nugroho \& Utama, 2014). Gejala yang timbul pada setiap individu berbeda namun gejala yang sering terjadi adalah kelelahan, sifat lekas marah, bengkak abdominal, dada sakit, suasana hati labil antara kesedihan dan kemarahan yang silih berganti serta depresi (Pratita R, 2016).

Berdasarkan data yang diperoleh dari Kementrian Kesehatan RI tahun 2014 tentang prevalansi pre-menstrual syndrome (PMS) di Indonesia, diperoleh hasil sebanyak $40 \%$ wanita Indonesia mengalami pre-menstrual syndrome (PMS) dan sebanyak 2-10\% mengalami gejala berat.

Penelitian Delara (2013), menunjukkan bahwa di Indonesia $66,3 \%$ remaja dengan
PMS ringan, 31,4\% dengan PMS sedang dan 2,3 dengan PMS berat. Penelitian yang dilakukan oleh American College of Obstetricians and Gynecologists (ACOG), pada tahun 2016 di Srilanka, didapatkan hasil bahwa remaja yang mengalami premenstrual syndrome (PMS), ada sekitar $65,7 \%$. Gejala yang sering muncul adalah perasaan sedih dan tidak berpengharapan sebesar 29,6\%. Di Mesir, prevalensi premenstrual syndrome (PMS), mencapai 69,9\% dan di Saudi Arabia mencapai 96,6\%.

Penelitian Presti (2016) didapatkan data $98,8 \%$ siswi mengalami pre-menstrual syndrome (PMS), serta menimbulkan kecemasan dengan tingkat sedang. Sebagian besar dari mereka bingung apa yang sedang mereka alami serta bagaimana cara mengatasinya. Akibatnya aktivitas sehari-hari menjadi terganggu, terutama siswi kurang berkonsentrasi ketika belajar di sekolah

Ada banyak faktor yang diduga menjadi penyebab timbulnya PMS. Salah satu faktor penyebab PMS yaitu kadar hormon estrogen yang berlebih, kadar hormon progesteron yang rendah, peningkatan hormon aldosteron, renin-angiotensin, serta hormon adrenal, kekurangan serotonin, kekurangan vitamin dan mineral (A, E, B6, Kalsium), hipoglikemi, hiperprolaktinemia (Haimd, M.A.A.E and Emam, E.A, 2013).

Kurangnya pengetahuan, pengalaman, dan juga kurangnya informasi yang dimiliki oleh wanita terutama oleh remaja putri tentang pre-menstrual syndrome (PMS), dapat memperberat gejala-gejala yang timbul. 
Terkadang remaja putri mencoba mengatasi gejala-gejala pre-menstrual syndrome (PMS) dan bersifat coba-coba tanpa adanya pengetahuan yang cukup dan benar (Suastina et al,. 2013).

Pengetahuan remaja tentang premenstrual syndrome (PMS), baik dari segi pengetahuan tentang tanda dan gejala maupun cara mengatasinya masih sangat kurang. Oleh sebab itu, sangat penting untuk meningkatkan pengetahuan remaja putri mengenai pre-menstrual syndrome (PMS), dengan meberikan pendidikan kesehatan tentang pre-menstrual syndrome (PMS) untuk mencegah terjadinya gangguan kesehatan tertuma yang disebabkan oleh premenstrual syndrome (PMS).

Media dan pembelajaran merupakan perantara untuk menyampaikan pesan atau informasi yang sangat dibutuhkan dalam proses pembelajaran agar memudahkan guru dalam penyampaian materi pembelajaran dan memudahkan siswa untuk menerima materi pembelajaran (Musfiqon, 2012). Pemilihan media sangatlah penting agar penyampaian informasi menjadi lebih menarik dan lebih mudah dipahami oleh penerima informasi. Ada beberapa media yang bisa digunakan dalam menyampaikan pendidikan kesehatan di sekolah misalnya dengan media visual, audio, audiovisual dan media cetak seperti poster, leaflate, booklet (Prastowo, 2012), setiap media yang akan diterapkan memiliki kelebihan dan kekurangan masing-masing.

Media audiovisual dan media cetak leaflet adalah salah satu media yang dapat digunakan dalam pemberian pendidikan kesehatan di sekolah mengenai pre-menstrual syndrome (PMS). Asyhar (2011: 45) mendefinisikan bahwa media audio visual adalah jenis media yang digunakan dalam kegiatan pembelajaran dengan melibatkan pendengaran dan penglihatan sekaligus dalam satu proses atau kegiatan. Pesan dan informasi yang dapat disalurkan melalui media ini dapat berupa pesan verbal dan nonverbal yang mengandalkan baik penglihatan maupun pendengaran. Beberapa contoh media audio visual adalah film, video, program TV dan lain-lain. Selain menggunakan media audiovisual pendidikan kesehatan di sekolah mengenai pre-menstrual syndrome (PMS) juga dapat dikombinasikan dengan menggunakan media cetak.

Media cetak adalah media yang menggunakan bahan dasar kertas atau kain untuk menyampaikan pesan-pesannya. Unsur-unsur utamanya adalah tulisan (teks), gambar visualisasi, atau keduanya. Media cetak bisa dibuat untuk membantu fasilitator melakukan komunikasi interpersonal saat pelatihan atau kegiatan kelompok, beberapa contoh dari media cetak yaitu poster, leaflet, booklet (Arsyad, 2011). Leaflet adalah bahan cetak tertulis berupa lembaran yang dilipat. Agar terlihat menarik biasanya leaflet didesain secara cermat dilengkapi dengan ilustrasi dan menggunakan bahasa yang sederhana, singkat serta mudah dipahami (Majid, 2014 :177).

Paket AViL-PMS atau Audiovisual Leaflet Pre-Menstrual Syndrome (PMS) 
adalah merupakan pendidikan kesehatan dengan menggunakan kombinasi media audiovisual dan media cetak (leaflet) yang yang berisi tentang pre-menstrual syndrome (PMS) dengan menggabungan dua media pendidikan kesehatan ini dianggap lebih menarik dan lebih berefek karena melibatkan dua indra yaitu pengelihatan dan pendengaran yang dapat memaksimalkan para remaja putri dalam penerimaan informasi dan pengetahuan mengenai premenstrual syndrome (PMS).

Informasi berupa pendidikan kesehatan dengan mengunakan media AViL-PMS atau kombinasi dari audiovisual dan leaflet tentang pre-menstrual syndrome (PMS), sangat penting diberikan pada siswi sehingga dapat memudahkan remaja puteri untuk memahami serta meningkatkan pengetahuan yang nantinya remaja putri dapat mengaplikasikannya dalam kehidupan sehari- hari. Pentingnya pengetahuan mengenai premenstrual syndrome (PMS), membuat peneliti tertarik untuk mengetahui pengaruh pendidikan kesehatan AViL-PMS tentang premenstrual syndrome (PMS) terhadap pengetahuan remaja puteri SMA "X" Kota Bandung.

Penelitian dilakukan untuk mengetahui pengaruh pendidikan kesehatan AViL-PMS terhadap pengetahuan remaja puteri di SMA "X" Kota Bandung.

\section{METODE PENELITIAN}

Rancangan penelitian yang digunakan yaitu Quasi Eksperiment Non Equivalent Pre-Post Design. Variabel penelitian yaitu Paket "AViL-PMS" dan pengetahuan remaja putri tentang pre-mentrual sindrom. Hipotesis penelitian yang diujikan "ada pengaruh Paket "AViL-PMS" terhadap pengetahuan remaja putri tentang pre-menstrual sindrom.

\section{Tabel 1 Definisi Operasional}

\begin{tabular}{|c|c|c|}
\hline Variabel & Definisi Operasional & Hasil dan Skala Ukur \\
\hline $\begin{array}{l}\text { Paket AViL-PMS tentang Pre- } \\
\text { Menstrual Syndrome (PMS) }\end{array}$ & $\begin{array}{l}\text { Pendidikan kesehatan tentang } \\
\text { pre-menstrual syndrome } \\
\text { (PMS) mengunakan media } \\
\text { audio visual dan leaflet }\end{array}$ & - \\
\hline Pengetahuan Remaja Puteri & $\begin{array}{l}\text { Pengetahuan remaja putri } \\
\text { mengenai pre-menstrual } \\
\text { syndrome (PMS) }\end{array}$ & $\begin{array}{l}\text { Hasil ukur: } 0-16 \\
\text { Skala Ukur: Rasio }\end{array}$ \\
\hline
\end{tabular}

Populasi penelitian adalah siswi SMA "X" Kota Bandung kelas X IPS yang berjumlah 74 siswi. Tehnik sampling menggunakan purposive dengan penentuan besar sampel sebanyak 42 .

Instrumen penelitian untuk mengukur pengetahuan remaja putri tentang pre- menstrual syndrome (PMS), menggunakan kuesioner. Kuesioner disusun berdasarkan teori yang terkait dengan pengetahuan premenstrual syndrom (PMS). Hasil uji validitas didapatkan rentang $\mathrm{r}$ 0,445-0,913 dengan reliabilitas sebesar 0,884 . 
Sumber data penelitian berupa data primer yang didapatkan dari kuesioner yang diisi langsung oleh siswi SMA " $\mathrm{X}$ " Kota Bandung setelah dilakukan pendidikan kesehatan AViL-PMS tentang pre-menstrual syndrome (PMS).

Pengumpulan data dilakukan sebanyak 2 kali berupa pretest dan posttest. Intervensi diberikan 2 hari setelah pre-test. Pedoman intervensi disusun dalam Pedoman Paket "AViL-PMS".

Pengolahan data meliputi pengeditan, pemberian kode, tabulasi, entri data dan pembersihan data. Analisis data menggunakan nilai rata-rata untuk univariat dan uji-T untuk bivariat.

\section{HASIL PENELITIAN}

Hasil penelitian menunjukkan terdapat perbedaan pengetahuan sebelum dan sesudah pemberian Paket "AViL-PMS” seperti yang tercantum pada tabel 2 .

Tabel 2 Pengetahuan Remaja Putri di SMA " $X$ " Kota Bandung $(n=42)$

\begin{tabular}{lcc}
\hline \multicolumn{1}{c}{ Pengetahuan } & rerata & Std. Dev \\
\hline Sebelum & 9,26 & 1,768 \\
Sesudah & 13,40 & 1,415 \\
\hline
\end{tabular}

Tabel 2 menunjukkan rerata pengetahuan sebelum dilakukan pendidikan kesehatan AViL-PMS yaitu 9,26 dan rata-rata pengetahuan sesudah dilakukan pendidikan kesehatan AViL-PMS yaitu 13,40.

Hasil uji hipotesis menunjukkan adanya pengaruh Paket "AViL-PMS" terhadap pengetahuan remaja putri seperti ditunjukkan tabel 3.

\section{Tabel 3 Pengaruh Paket AViL-PMS Terhadap Pengetahuan Remaja Puteri SMA "X" Kota Bandung $(\mathbf{n}=42)$}

\begin{tabular}{lccc}
\hline \multicolumn{1}{c}{ Pengetahuan } & Rerata \pm s.b & $\begin{array}{c}\text { Perbedaan } \\
\text { Rerata } \pm \text { s.b }\end{array}$ & P-value IK95\% \\
\hline Sebelum & $9,26 \pm 0,273$ & $3,78 \pm 0,249$ & 0.000 \\
Sesudah & $13,40 \pm 0,218$ & & $3,639-4,647$ \\
\hline
\end{tabular}

Tabel 3 menunjukkan perbedaan rerata pengetahuan remaja puteri sebelum dan sesudah diberikan Paket AViL-PMS sebesar $3,78 \pm 0,249$ dengan $p$-value $=0,000<\alpha=$ 0,005 yang berarti Ha gagal ditolak yaitu terdapat pengaruh yang signifikan dari pendidikan kesehatan AViL-PMS terhadap pengetahuan remaja puteri tentang premenstrual syndrome (PMS) di SMA "X" Kota Bandung.

\section{PEMBAHASAN}

Pengetahuan tentang pre-menstrual syndrome (PMS) meliputi pengertian, penyebab, gejala, jenis-jenis, pencegahan, dan penanganan. Hasil penelitian ini menunjukkan pengetahuan remaja puteri sebelum dilakukan pendidikan kesehatan AViL-PMS tentang pre-menstrual syndrome (PMS) ratarata adalah 9,26. Rerata tersebut menunjukkan bahwa lebih dari setengah 
remaja puteri dapat menjawab kuesioner dengan benar dan sebagian masih banyak yang menjawab salah. Rata-rata remaja putri salah ketika menjawab kuesioner yang berisi tentang penyebab, gejala-gejala, dan penanganan pre-menstrual syndrome (PMS).

Sebagian besar remaja putri menyebutkan bahwa yang menyebabkan terjadinya pre-menstrual syndrome (PMS) adalah ketidak seimbangan kadar oksigen dalam tubuh. Menurut Nugroho \& Utama (2014) pre-menstrual syndrome (PMS), terjadi karena tidak keseimbangan antara hormon estrogen.

Pengetahuan kurang tepat ditunjukkan oleh remaja yang menyebutkan payudara terasa kencang dan teraba keras merupakan salah satu ciri awal menstruasi yang termasuk dalam gejala. Remaja puteri banyak menjawab bawah payudara terasa kencang dan teraba keras termasuk dalam gejala psychologic symptoms. Akan tetapi jawaban yang benar adalah payudara terasa kencang dan teraba keras termasuk dalam gejala physical symptoms. Menurut Pawesti \& Untari (2015), salah satu gejala preMenstrual Syndrome (PMS) adalah physical symptoms, atau secara fisik muncul gejala sakit kepala, payudara bengkak serta teraba keras, nyeri punggung, nyeri perut dan rasa penuh, bengkak pada kaki dan tangan, mual, nyeri otot dan persendian.

Kuesioner penangan pre-Menstrual Syndrome (PMS), juga rata-rata dijawab salah oleh remaja puteri, pertanyaan tersebut berisi tentang, pola hidup sehat seperti, mengurangi kafein, memperbanyak waktu istirahat dapat mengurangi gejala premenstrual syndrome (PMS) seperti. Remaja puteri rata-rata menjawab bahwa pola hidup sehat seperti, mengurangi kafein, memperbanyak waktu istirahat dapat mengurangi gejala pre-menstrual syndrome (PMS) seperti, nyeri persendian dan penambahan berat badan. Jawaban yang benar adalah pola hidup sehat seperti, mengurangi kafein, memperbanyak waktu istirahat dapat mengurangi gejala premenstrual syndrome (PMS), seperti kelelahan dan stres. Jawaban ini sesuai dengan teori Saryono dkk (2009), dimana salah satu penanganan pre-menstrual syndrome (PMS) dapat dilakukan adalah modifikasi gaya hidup, dengan cara melakukan pola hidup sehat seperti, mengurangi kafein, memperbanyak waktu istirahat hal ini bertujuan untuk menghindari kelelahan, dan mengurangi stres berperan juga dalam terapi pre-menstrual syndrome (PMS).

Menurut peneliti, penyebab sebagian besar remaja puteri menjawab salah pada pertanyaan tentang penyebab, gejala-gejala, dan penanganan pre-menstrual syndrom (PMS), disebabkan kurangnya informasi yang didapat responden tentang premenstrual syndrome (PMS). Salah satu faktor dari sebagian remaja puteri masih banyak mejawab kuesioner tentang pre-menstrual syndrom (PMS) dengan salah dikarenakan responden merupakan remaja puteri dari kelas X IPS dimana remaja puteri tersebut tidak pernah mendapatkan informasi tentang 
pre-menstrual syndrom (PMS) dan juga di jurusan IPS tidak ada pendidikan atau pelajaran tentang sistem reproduksi yang biasanya dipelajari anak IPA. Oleh karena itu pengetahuan remaja puteri kelas X IPS tentang pre-menstrual syndrom (PMS) masih terbatas dikarenakan kurangnya informasi tentang pre-menstrual syndrome (PMS).

Berdasarkan hasil wawancara terhadap guru penanggung jawab UKS didapatkan bahwa di sekolah belum pernah ada yang memberikan pendidikan kesehatan, ataupun penyuluhan terkait pre-menstrual syndrome (PMS). Sementara remaja puteri saat ini sangat membutuhkan informasi tentang premenstrual syndrome (PMS) untuk meningkatkan pengetahuan tentang premenstrual syndrome (PMS). Hal ini sesuai dengan teori Notoatmodjo (2011) dan Budiman (2013), faktor yang mempengaruhi pengetahuan adalah sosial-ekonomi, tingkat pendidikan, informasi, kultur (budanya dan agama), dan pengalaman.

Pengetahuan remaja puteri setelah dilakukan pemberian pendidikan kesehatan AViL-PMS tentang pre-menstrual syndrome (PMS) rata-rata adalah 13,40. Rata-rata tersebut mengalami peningkatan dan dapat dikatakan bahwa hampir seluruh remaja puteri dapat menjawab kuesioner tentang premenstrual syndrome (PMS) dengan benar. Sebelum dilakukan pendidikan kesehatan AViL-PMS tentang pre-menstrual syndrome (PMS), rata-rata remaja puteri salah ketika menjawab kuesioner yang berisi tentang penyebab, gejala-gejala, dan penanganan premenstrual syndrome (PMS).

Akan tetapi setelah dilakukan pendidikan kesehatan AViL-PMS kuesioner tentang penyebab dengan pertanyaan, apa yang menyebabkan terjadinya pre-menstrual syndrome (PMS), sebagian besar remaja puteri sudah menjawabnya dengan benar dimana yang menyebabkan terjadinya premenstrual syndrome (PMS) adalah ketidak seimbangan hormon esterogen (Nugroho \& Utama, 2014). Namun sebagian kecil remaja puteri masih memilih jawaban yang salah yaitu ketidak seimbangan kadar oksigen didalam tubuh.

Untuk kuesioner tentang gejala-gejala pre-menstrual syndrome (PMS) dengan pertanyaan, payudara terasa kencang dan teraba keras merupakan salah satu ciri awal menstruasi yang termasuk dalam gejala. ini juga didapatkan bahwa sebagian remaja puteri telah menjawab pertanyaan tersebut dengan benar, dimana jawaban yang benar yaitu physical symptoms (Pawesti \& Untari (2015). Sama halnya dengan kuesioner tentang penyebab pre-menstrual syndrome (PMS), sebagian kecil remaja puteri masih memilih jawaban yang salah yaitu psychologic symptoms. Psychologic Symptoms merupakan salah satu dari gejalagelaja pre-menstrual syndrome (PMS), akan tetapi gejala yang ditimbulkan dari psychologic symptoms adalah mudah tersinggung, mudah marah, depresi, mudah sedih, cengeng, cemas, susah konsentrasi, 
bingung, sulit istirahat dan merasa kesepian (Pawesti \& Untari, 2015).

Selain itu remaja puteri juga sebagian besar telah menjawab pertanyaan tentang penanganan pre-menstrual syndrome (PMS) dengan benar. Sebelumnya kuesioner penganan pre-menstrual syndrome (PMS) yang isinya tentang, pola hidup sehat seperti, mengurangi kafein, memperbanyak waktu istirahat dapat mengurangi gejala premenstrual syndrome (PMS), seperti. Sebagian besar dijawab salah yaitu dengan memilih nyeri persendian dan penambahan berat badan. Akan tetapi setelah dilakukan pendidikan kesehatan AViL-PMS, sebagian besar remaja telah menjawab kuesioner dengan benar yaitu pola hidup sehat seperti, mengurangi kafein, memperbanyak waktu istirahat dapat mengurangi gejala premenstrual syndrome (PMS), seperti kelelahan dan stres. Jawaban ini sesuai dengan teori Saryono dkk (2009).

Berdasarkan hasil penelitian tersebut dapat dilihat bahwa penggunaan AViL-PMS dalam penyampaian pendidikan kesehatan dapat memberikan pengaruh terhadap pengetahuan remaja puteri. Hasil penelitian ini sesuai dengan teori Nursalam (2013), pendidikan kesehatan adalah proses yang direncanakan dengan sadar untuk menciptakan peluang bagi individu-individu untuk senantiasa belajar memperbaiki kesadaran (literacy) serta meningkatkan pengetahuan dan keterampilannya (life skills) demi kepentingan kesehatannya. Pengetahuan tentang pre-menstrual syndrome
(PMS) yang baik diharapkan nantinya remaja puteri memiliki sikap dan perilaku yang positif tentang kesehatan reproduksi khususnya tentang pre-menstrual syndrome (PMS).

Selain itu peningkatan pengetahuan remaja puteri tentang pre-menstrual syndrome (PMS) dipengaruhi oleh penggunaan media pendekatan pendidikan kesehatan yang digunakan. Media pendidikan kesehatan, menurut Nursalam (2011) adalah saluran komunikasi yang dipakai untuk mengirimkan pesan kesehatan. Media pendidikan kesehatan, pada dasarnya dapat membantu sasaran pendidik untuk menerima pelajaran kesehatan dengan menggunakan panca inderanya. Alat peraga disusun berdasarkan prinsip bahwa pengetahuan manusia tentang pemahaman informasi ditangkap oleh panca indera. Semakin banyak indra yang digunakan dalam menangkap informasi maka akan mempermudah seseorang untuk mendapatkan kesimpulan terhadap informasi.

Dalam penelitian ini peneliti membuat media pendidikan kesehatan berupa AViLPMS. AViL-PMS adalah gabungan dari media Audiovisual dan Leaflet tentang premenstrual syndrome (PMS). Peneliti memilih menggabungkan dua media pendidikan kesehatan ini dikarenakan ingin mengetahui apakah dengan menggabungan dua media yang berbeda cara penggunaanya akan efektif jika diberikan kepada remaja puteri di SMA "X" Kota Bandung. Kombinasi dari media audiovisual dan media cetak (leaflet) yang 
yang berisi tentang pre-menstrual syndrome (PMS) dianggap lebih menarik dan lebih berefek karena melibatkan dua indra yaitu pengelihatan dan pendengaran yang dapat memaksimalkan para remaja puteri dalam penerimaan informasi dan pengetahuan mengenai pre-menstrual syndrome (PMS). Ketika dilakukan pendidikan kesehatan AViL-PMS remaja puteri terlihat bersemangat dan ketika dilakukan evaluasi dan post-test dapat dilihat pengetahuan remaja puteri tentang pre-menstrual syndrom PMS) meningkat.

Secara konsep dapat disimpulkan bahwa pendidikan kesehatan adalah upaya untuk mempengaruhi orang lain baik individu, kelompok, atau masyarakat agar melaksanakan perilaku hidup sehat. Secara operasional pendidikan kesehatan adalah semua kegiatan untuk memberikan, meningkatkan pengetahuan, sikap, dan praktik masyarakat dalam memelihara dan meningkatkan kesehatan.

Tabel 3 menunjukkan terdapat perubahan rata-rata pengetahuan remaja putri tentang pre-menstrual syndrome sebelum dan sesudah diberikan pendidikan kesehatan AViL-PMS tentang pre-menstrual syndrome (PMS), dimana sebelum dilakukan pendidikan kesehatan AViL-PMS sebagaian remaja puteri telah menjawab kuesioner dengan benar akan tetapi masih banyak remaja putri yang menjawab kuesioner dengan salah dan rata-rata remaja puteri menjawab salah pada kuesioner tentang penyebab, gejala-gejala, dan penanganan pre- menstrual syndrome (PMS). Akan tetapi setelah dilakukan pendidikan kesehatan AViL-PMS, sebagian besar remaja puteri dapat menjawab kuesioner dengan benar termasuk kuesioner tentang penyebab, gejalagejala, dan penanganan pre-menstrual syndrome (PMS).

Pengetahuan remaja puteri yang meningkat dipengaruhi oleh diberikannya informasi tentang pre-menstrual syndrome (PMS) melalui pendidikan kesehatan AViL$P M S$ yang berisi suara dan gambar sehingga tidak membosankan dan diterima oleh dua indra yaitu pengelihatan dan pendengaran. Adanya pengaruh pendidikan kesehatan AViL-PMS terhadap peningkatan pengetahuan remaja puteri tentang premenstrual syndrome (PMS) di SMA " $\mathrm{X}$ " Kota Bandung ditunjukan pada tabel 4.2 yaitu pengetahuan remaja puteri setelah di berikan pendidikan kesehatan AViL-PMS yaitu sebesar 3,78 $\pm 0,249$, data tersebut menunjukkan bahwa dari 42 remaja puteri, sebagian besar remaja puteri sudah menjawab kuesioner dengan benar dan sedikit remaja puteri yang masih menjawab kuesioner salah setelah dilakukan pendidikan kesehatan AViL-PMS. Sementara $p$-value $=0,000<\alpha=$ 0,005, hasil uji tersebut menunjukan adanya pengaruh pendidikan kesehatan AViL-PMS tentang pre-menstrual syndrome (PMS) terhadap pengetahuan remaja puteri di SMA Pasundan 1 Kota Bandung. Pada Penelitian ini dapat diartikan bahwa sebagian besar remaja puteri telah mengetahui tentang pre- 
menstrual syndrome (PMS) setelah dilakukan pendidikan kesehatan AViL-PMS.

Dari hasil penelitian, pendidikan kesehatan AViL-PMS ini sangat efektif untuk diberikan kepada remaja puteri. AViL-PMS itu sendiri adalah tema yang dibuat oleh peneliti dengan bantuan dosen pembimbing yang bertujuan untuk membuat konsep baru dalam melakukan pendidikan kesehatan yang efektif untuk diberikan kepada remaja puteri agar remaja putri dapat dengan cepat memahami materi pendidikan kesehatan yang diberikan, sehingga remaja putri dapat memiliki pengetahuan baru tentang kesehatan khususnya tentang pre-menstrual syndrom (PMS) dengan baik.

Media dalam pendidikan kesehatan ini adalah media audiovisual dan media cetak (leaflet) yang kemudian di kombinasikan dan berisi tentang pre-menstrual syndrome (PMS) dengan menggabungan dua media pendidikan kesehatan ini dianggap lebih menarik dan lebih berefek karena melibatkan dua indra yaitu pengelihatan dan pendengaran yang dapat memaksimalkan para remaja puteri dalam penerimaan informasi dan pengetahuan mengenai premenstrual syndrome (PMS). Media audiovisual, yaitu media yang merupakan kombinasi audio dan visual atau bisa disebut media pandang-dengar dan salah satu kelebihanya adalah lebih menarik dan lebih berefek karena melibatkan dua indra yaitu pengelihatan dan pendengaran yang dapat memaksimalkan penerimaan informasi. Sementara media cetak (Leaflet) sangat efektif untuk menyampaikan pesan yang singkat dan padat seperti poster, media ini juga mudah dibawa dan disebarluaskan. Bahkan karena ukurannya yang lebih ringkas, jumlah yang dibawa bisa lebih banyak daripada poster (Azul, 2010: 7).

Hasil penelitian ini sesuai dengan hipotesis yang telah disusun didalam penelitian yaitu terdapat pengaruh pendidikan kesehatan AVIL-PMS tentang pre-menstrual syndrome (PMS) terhadap pengetahuan remaja puteri SMA “X” Kota Bandung.

Hasil penelitian ini menunjukan bahwa pengunaan media audiovisual dan leaflet dalam melakukan pendidikan kesehatan dapat mempengaruhi pengetahuan remaja putri tentang pre-menstrual syndrom (PMS). Hasil penelitian ini sesuai dengan penelitian yang dilakukan oleh Dwi Estri (2017), yang menyimpulkan bahwa pemberian pendidikan kesehatan menggunakan media audiovisual dapat mempengaruhi dan meningkatkan pengetahuan remaja tentang pentingnya pendidikan kesehatan yang diberikan.

\section{KESIMPULAN}

Penelitian menyimpulkan bahwa Paket "AViL-PMS" berpengaruh terhadap pengetahuan remaja putri tentang premenstrual syndrome yang ditunjukkan dengan nilai p sebesar 0.000 . 


\section{DAFTAR PUSTAKA}

Abdul, Majid. 2014. Strategi Pembelajaran. Bandung : PT Remaja Rosdakarya

Agus, Sulistyo. 2014. Pengaruh Penyuluhan Terhadap Perilaku Penanganan Sindrom Pra Haid Pada Siswi Kelas XI Di Madarasah Aliyah Negeri Yogyakarta. Skripsi. STIKes Aisyah Yogyakarta

Arsyad, Azhar. 2011. Media Pembelajaran. Jakarta: Raja Grafindo Persada

Asyhar, Rayanda. 2011. Kreatif Mengembangkan Media Pembelajaran. Gaung. Persada (GP) Press Jakarta

BKKBN. 2012. Pedoman Pengelolaan Pusat Informasi Dan Konseling Remaja Dan Mahasiswa (PIK R/M). Badan Kependudukan Dan Keluarga Berencana Nasional Direktorat Bina Ketahanan Remaja : Jakarta

Budiman, dan Riyanto, Agus. 2013. Pengetahuan dan Sikap Dalam Penelitian Kesehatan. Jakarta : Salemba Medika

Haimd, M.A.A.E., Moghazi, D.A.E., Moustafa, M.F., and Emam, E.A. 2013. Knowladge and Practice of Female Employee About Premenstrual
Syndrome and its Effect on Daily Life Activities in Elminia University. Life Science Journal, 10 (1) : 234-243.

Irianto, K. 2015. Kesehatan Reproduksi (Reproduktive Health) Teori dan Praktikum. Bandung: Alfabeta.

KemenKes RI. 2015. Infodatin: Situasi Kesehatan Reproduksi Remaja. Jakarta: Kementerian Kesehatan RI.

Musfiqon. 2012. Pengembangan Media dan Sumber Pembelajaran. Jakarta : Prestasi Pustaka

Notoatmodjo, Soekidjo. 2011. Promosi Kesehatan Teori dan Aplikasi. Jakarta. Rineka Cipta

Nugroho. T., Utama. B. I. 2014. Masalah Kesehatan Reproduksi Wanita. Yogyakarta: Nuha Medika

Nursalam. 2011. Manajemen Keperawatan Aplikasi Dalam Praktik Keperawatan Professional. Edisi 3. Jakarta : Salemba Medika

Presti, O, H. 2016. Hubungan Pre Menstrual Syndrome dengan Tingkat Kecemasan pada Remaja. Skripsi. Yogyakarta : Universitas Muhammadiyah Yogyakarta. 